\title{
Prevalence of undiagnosed COPD in male patients with coronary artery disease: a cross- sectional study in Jordan
}

This article was published in the following Dove Press journal: International Journal of COPD

\author{
Basheer Y Khassawneh' \\ Shaher M Samrah' \\ Mohamad I Jarrah' \\ Rasheed K Ibdah' \\ Ali M Ibnian' \\ Abdelhameed W \\ Almistarehi' \\ Aseel A Zghayer' \\ Saddam I Abuqudairi' \\ Yousef S Khader ${ }^{2}$ \\ 'Department of Internal Medicine, \\ Public Health and Family Medicine, \\ Faculty of Medicine, Jordan University \\ of Science and Technology, Irbid, \\ Jordan; ${ }^{2}$ Department of Community \\ Medicine, Public Health and Family \\ Medicine, Faculty of Medicine, Jordan \\ University of Science and Technology, \\ Irbid, Jordan
}

Correspondence: Basheer Y Khassawneh Department of Internal Medicine, Faculty of Medicine, Jordan University of Science and Technology, P O Box 3030, Irbid 22110, Jordan

Tel +96272600 ext 40702

Fax +962 7200624

Email basheerk@just.edu.jo
Purpose: COPD and coronary artery disease (CAD) are common chronic diseases with shared risk factors. COPD continues to be largely underdiagnosed and undertreated. We aimed to describe the prevalence and predictors of undiagnosed COPD in Jordanian men with CAD.

Patients and methods: In a cross-sectional study conducted at a referral center in Jordan, male patients who underwent coronary angiography for suspected CAD and reported $\geq 10$ pack-year of cigarette smoking were recruited. Pre- and post-bronchodilator spirometry was undertaken for all participants, and COPD was defined as post-bronchodilator $\mathrm{FEV}_{1} / \mathrm{FVC}<70 \%$. The finding of $\geq 50 \%$ coronary luminal narrowing confirmed the presence of CAD.

Results: Spirometry was undertaken for 376 men with mean age of $56.02 \pm 10.55$ years, and $72.6 \%$ were active cigarettes smokers with a mean pack-year of $55.89 \pm 34.25$. A CAD diagnosis was confirmed in $300(79.8 \%)$ men. Spirometric criteria for COPD were met in 76 (15.7\%) patients, of whom $91.5 \%$ were not previously diagnosed. COPD-related symptoms were common: chronic cough (44.4\%), dyspnea (66.2\%), and wheezes (27.9\%). COPD was more common in patients with $(18.0 \%)$ compared to patients without $(6.6 \%) \mathrm{CAD}(P=0.014)$. Multivariate logistic regression showed that the risk of COPD was higher in patients with CAD (OR 3.16, 95\% CI, 1.10-9.09, $P=0.033$ ) and in those with chronic bronchitis (OR 13.07, 95\% CI, 6.69-25.52, $P<0.001)$.

Conclusion: There was a high prevalence of COPD among male patients with CAD and most were underdiagnosed despite having respiratory symptoms. Male smokers with CAD and respiratory symptoms should be evaluated for airflow limitation and the presence of COPD.

Keywords: COPD, cardiovascular disease, coronary catheterization, airflow limitation, spirometry

\section{Introduction}

COPD is a common and preventable respiratory disease characterized by persistent symptoms and airflow limitation, caused mainly by exposure to tobacco smoking. ${ }^{1}$ COPD is the fourth leading cause of death in the world and is projected to be the third leading cause of death by $2020 ;{ }^{2}$ it continues to be an important health burden. ${ }^{1}$

Patients with COPD commonly have comorbidities, including coronary artery disease (CAD), which may complicate treatment and increases the morbidity and mortality of the affected individuals. Furthermore, CAD continues to be the leading cause of disability and death in subjects older than 35 years $^{3,4}$ and accounts for half of all cardiovascular deaths in the United States. ${ }^{3}$ The coexistence of COPD and CAD is expected, given the shared common risk factor of cigarette smoking and the increased prevalence of both diseases with advancing age. Moreover, systematic inflammation 
in COPD, ${ }^{5}$ increased arterial stiffness, and endothelial dysfunction are potential modifiable mechanisms of cardiovascular morbidity and mortality in patients with COPD. ${ }^{6}$

The reported prevalence of CAD in patients with COPD can be up to $60 \%$, with a relative risk of $\mathrm{CAD}$ as high as seven-fold. ${ }^{7}$ Furthermore, risk factors for CAD are common in individuals with COPD. ${ }^{8}$ Although the prevalence of COPD in patients with CAD is not widely reported, available reports show that it ranges from $10.5 \%$ to $33.6 \%$ and most cases of COPD were not previously diagnosed. ${ }^{9-12}$ Lastly, patients with CAD who have coexisting COPD have increased morbidity and mortality, ${ }^{12,13}$ whereas cardiovascular disease comorbidity is an important cause of mortality in patients with COPD. ${ }^{14}$

Prevalence and impact of both CAD and COPD is projected to increase in developing countries due to growing exposure to risk factors and an expected increase in the rate of tobacco consumption. ${ }^{15}$ Despite the relatively young population, the prevalence of COPD across the Middle East region is $3.6 \%{ }^{16}$ and COPD is still largely underdiagnosed and undertreated. ${ }^{17}$ Given the scarcity of evidence on the association between COPD and CAD in developing countries and in the Middle East region in particular, ${ }^{18,19}$ this study was conducted to describe the prevalence and predictors of COPD among male Jordanian smokers with angiographically proven CAD.

\section{Material and methods}

A cross-sectional study was conducted at the Prince Muna Cardiac Center, King Abdullah University Hospital in the northern part of Jordan. The hospital is a 600-bed referral center for a population of 2.8 million (one third of the Jordanian population). This study was approved by the Institutional Review Board of Jordan University of Science and Technology, and participants provided written informed consent. All adult male patients who underwent coronary angiography (CATH) for suspected CAD and had a history of cigarette smoking ( $\geq 10$ pack-year) were recruited for the study. We excluded patients who were 1) unable to undertake spirometry testing (intubated, in shock, acute pulmonary edema, and patient with active angina pain) and 2) patients with a history of bronchial asthma or bronchiectasis.

During a single face-to-face encounter, sociodemographic data, smoking history, previous diagnosis of COPD, and risk factors for CAD were obtained. COPD-related symptoms were derived from the Arabic version of the Clinical COPD Questionnaire. ${ }^{20}$ Pre- and post-bronchodilator spirometry using a portable spirometer (FlowScreen ${ }^{\circledR} \mathrm{CT}$; eResearch
Technology GmbH, Höchberg, Germany) was conducted during the same session. Spirometry was undertaken by trained study coordinators and the results were interpreted by a staff pulmonologist according to standard guidelines. ${ }^{21,22}$ The device was calibrated on each testing day, according to the manufacturers' instructions. The test was clearly explained and demonstrated to each participant. Forced expiratory maneuvers were repeated until three reproducible acceptable readings were obtained and the best $\mathrm{FEV}_{1}, \mathrm{FVC}$, and $\mathrm{FEV}_{1} / \mathrm{FVC}$ ratios were used. The post-bronchodilator test was conducted during the same session for patients with a pre-bronchodilator $\mathrm{FEV}_{1} / \mathrm{FVC}$ ratio of less than $70 \%$ and 15 minutes after the inhalation of $400 \mu \mathrm{g}$ salbutamol from a metered-dose inhaler (Ventolin ${ }^{\circledR}$; GlaxoSmithKline plc, London, UK). COPD was defined as the presence of post-bronchodilator $\mathrm{FEV}_{1} / \mathrm{FVC}$ of less than $70 \%$. Airflow limitation was graded according to the Global Initiative for Obstructive pulmonary Disease (GOLD) classification into GOLD $1\left(\mathrm{FEV}_{1} \geq 80 \%\right)$, GOLD $2\left(80 \%>\mathrm{FEV}_{1} \geq 50 \%\right)$, GOLD $3\left(50 \%>\mathrm{FEV}_{1} \geq 30 \%\right)$, and GOLD $4\left(\mathrm{FEV}_{1}<30 \%\right)$ stages. Chronic bronchitis was defined as having cough and sputum production for at least 3 months in each of two consecutive years. CATH procedures were carried out and reported by a staff cardiologist using a Philips coronary angiography device (Allura Xper FD10 $\backslash 10$ Clarity, Phillips, Amsterdam, the Netherlands). Patients with luminal coronary vessel narrowing $\geq 50 \%$ were considered to have CAD.

\section{Statistical analysis}

The IBM Statistical Package for Social Sciences software (SPSS) for Windows, Version 24.0 (IBM Corp, Armonk, NY, USA) was used for data processing and analysis. Characteristics of the subjects' variables were described using frequency distribution for categorical variables and mean and SD for continuous variables. Tests of significance between groups were carried out using the chi-squared test or Fisher's exact test for categorical variables, whereas continuous variables were first examined for deviation from normality at $P<0.01$ (Levene's test) and, after demonstrating a normal distribution, the Student's $t$-test or ANOVA were conducted. Post hoc comparative analysis was conducted between different treatment groups of CAD and in those without CAD using Tukey's HSD test. Multivariate logistic regression analysis with backward elimination was conducted (OR, elimination threshold $P>0.1$ ) to determine the predictors of COPD, including age, active smoking vs ex-smoking, presence of CAD, chronic bronchitis, and symptoms of chough, dyspnea, and wheezes. The results of the logistic regression 
analysis were presented as ORs and their 95\% CIs. A $P$-value of $<0.05$ was considered statistically significant for all analyses conducted.

\section{Results \\ Participants}

Between July and December 2017, a total of 785 patients underwent CATH, 427 (54.4\%) met our cigarette-smoking criteria, and 413 (96.7\%) were males. Thirty-seven patients were excluded for being unable/unwilling to complete spirometry $(n=29)$ or for having bronchial asthma $(n=8)$. Clinical data and spirometry were completed for 376 participants $(91.0 \%)$ and were included in the analysis (Figure 1).

Mean age of all participants was $56.02 \pm 10.55$ years (range $21-85$ years) and most were active cigarette smokers $(273 ; 72.6 \%)$ with a mean pack-year of $55.89 \pm 34.25$ (range 10-240). Symptoms of COPD were common; 167 (44.4\%) patients with chronic cough, 249 (66.2\%) with dyspnea, $105(27.9 \%)$ with wheezing, and $89(23.7 \%)$ met the clinical criteria of chronic bronchitis. CATH results showed that $300(79.8 \%)$ had coronary angiographic evidence of CAD $-249(83.0 \%)$ were treated with percutaneous coronary angioplasty (PCI), 33 (11.0\%) were referred for coronary artery bypass surgery $(\mathrm{CABG})$, and $18(6.0 \%)$ received medical therapy. Patients with CAD were older $(P=0.008)$, had more diabetes mellitus $(P=0.037)$ and hypertension $(P=0.028)$, and had greater airflow limitation with lower $\mathrm{FEV}_{1}$ $(P=0.034)$ and lower $\mathrm{FEV}_{1} / \mathrm{FVC}$ ratio $(P=0.038)$. There was no difference in smoking habits, presence of hyperlipidemia, frequency of respiratory symptoms, or body mass index (BMI) between those with and without CAD (Table 1).

\section{Chronic obstructive lung disease}

Table 2 describe the demographics, symptoms, and spirometry findings in patients with and without COPD. Fiftynine patients $(15.7 \%)$ met the GOLD criteria of COPD and $12(20.3 \%)$ had GOLD 1, 40 (67.8\%) had GOLD 2, and $7(11.9 \%)$ had GOLD 3. The majority of patients with COPD (54; 91.5\%) were not previously diagnosed. Patient with COPD were older $(P<0.001)$, had higher smoking intensity $(P=0.009)$, had lower BMI $(P=0.001)$, and had more COPD-related symptoms $(P<0.001)$ than those who did not have COPD. The prevalence of COPD increased with age from $6.5 \%$ in patients $<50$ years old to $37.5 \%$ in

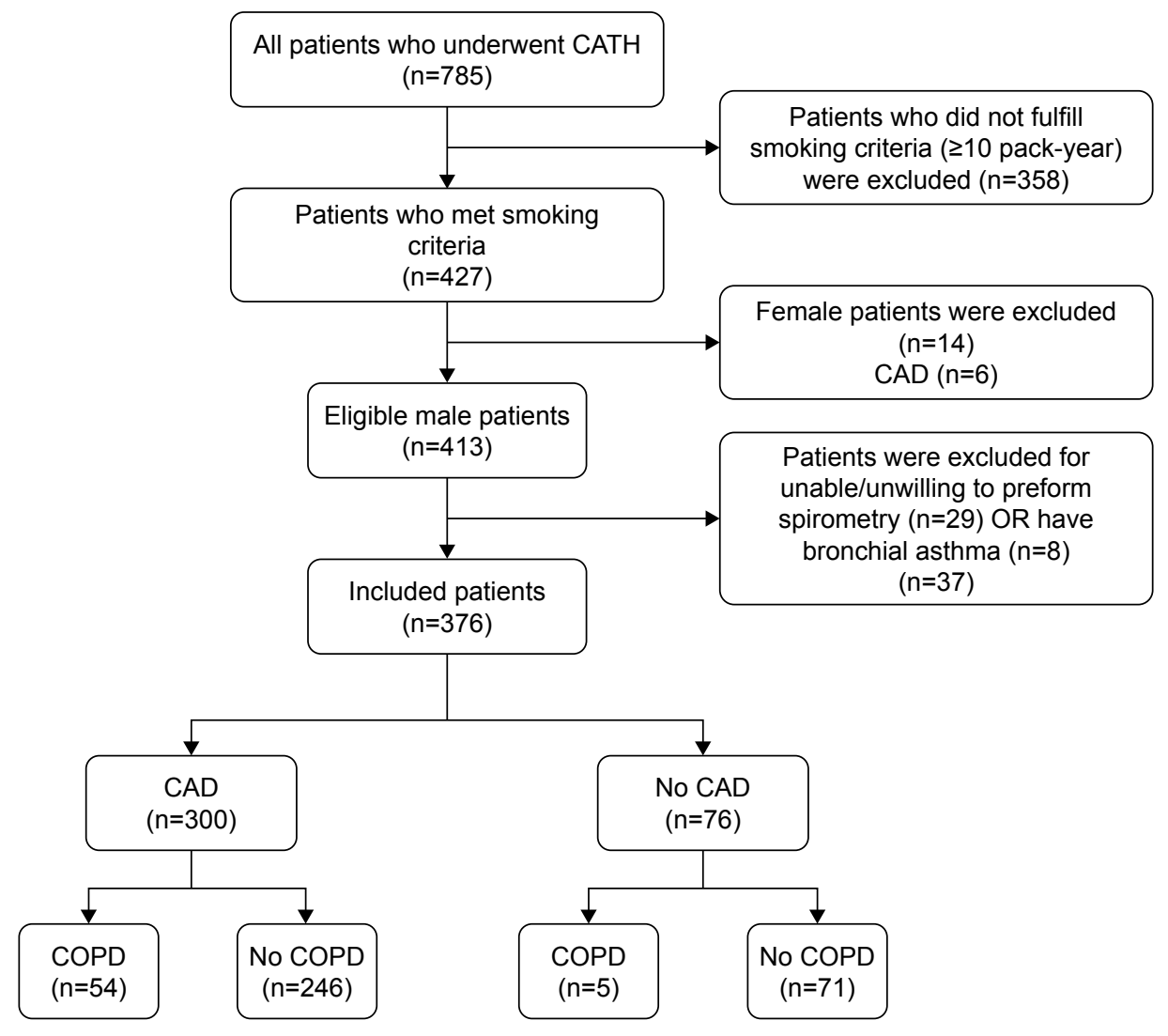

Figure I Flow chart of study participants showing excluded patients at different stages of the study. Abbreviation: CAD, coronary artery disease. 
Table I Characteristics of the participants according to the coronary artery disease status

\begin{tabular}{|c|c|c|c|c|}
\hline Characteristic & $\begin{array}{l}\text { All } \\
n=376\end{array}$ & $\begin{array}{l}\text { CAD } \\
n=300\end{array}$ & $\begin{array}{l}\text { No CAD } \\
n=76\end{array}$ & $P$-value \\
\hline Age, years mean $\pm S D$ & $56.02 \pm 10.55$ & $56.75 \pm 10.14$ & $53.16 \pm 11.65$ & 0.008 \\
\hline Diabetes mellitus, n (\%) & | 48 (39.4) & $126(42.0)$ & $22(28.9)$ & 0.037 \\
\hline Hypertension, n (\%) & $257(68.4)$ & $213(71.0)$ & $44(57.9)$ & 0.028 \\
\hline Hyperlipidemia, n (\%) & $100(26.6)$ & $79(26.3)$ & $21(27.6)$ & 0.819 \\
\hline Current smoker, n (\%) & $273(72.6)$ & $216(72.0)$ & $57(75.0)$ & 0.600 \\
\hline Pack-year, mean $\pm S D$ & $55.89 \pm 34.25$ & $56.8 \mathrm{I} \pm 35.47$ & $52.22 \pm 28.88$ & 0.297 \\
\hline Body mass index, mean $\pm S D$ & $28.90 \pm 4.95$ & $28.78 \pm 4.75$ & $29.42 \pm 5.68$ & 0.321 \\
\hline Chronic cough, n (\%) & $167(44.4)$ & $139(46.3)$ & $28(36.8)$ & 0.137 \\
\hline Dyspnea, n (\%) & $249(66.2)$ & $198(66.0)$ & $51(67.1)$ & 0.856 \\
\hline Wheezes, n (\%) & $105(27.9)$ & $83(27.7)$ & $22(28.9)$ & 0.824 \\
\hline Chronic bronchitis, n (\%) & $89(23.7)$ & $73(24.3)$ & I6 (2I.I) & 0.548 \\
\hline Previous COPD diagnosis, n (\%) & $9(2.4)$ & $8(2.7)$ & I (I.3) & $0.693^{\mathrm{a}}$ \\
\hline COPD (GOLD criteria) & $59(15.7)$ & $54(18.0)$ & $5(6.6)$ & 0.014 \\
\hline \multicolumn{5}{|l|}{ Pre-bronchodilator } \\
\hline $\mathrm{FEV}_{1}, \mathrm{~L}$ & $2.61 \pm 0.72$ & $2.57 \pm 0.7 \mid$ & $2.77 \pm 0.74$ & 0.034 \\
\hline $\mathrm{FEV}_{1}, \%$ predicted & $79.68 \pm 16.57$ & $78.943 \pm 16.44$ & $82.57 \pm 16.88$ & 0.089 \\
\hline FVC, L & $3.22 \pm 0.89$ & $3.20 \pm 0.90$ & $3.31 \pm 0.88$ & 0.367 \\
\hline FVC, \% predicted & $78.52 \pm 15.83$ & $78.04 \pm|5.7|$ & $80.42 \pm 16.25$ & $0.24 I$ \\
\hline $\mathrm{FEV}_{1} / \mathrm{FVC}$ ratio & $81.01 \pm 9.54$ & $80.50 \pm 9.95$ & $83.04 \pm 7.46$ & 0.038 \\
\hline
\end{tabular}

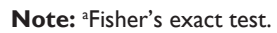

Abbreviations: CAD, coronary artery disease; GOLD, Global Initiative for Chronic Obstructive Lung Disease.

Table 2 Characteristics and spirometry findings of participants with chronic obstructive lung disease

\begin{tabular}{|c|c|c|c|}
\hline Characteristic & $\begin{array}{l}\text { No COPD } \\
n=317\end{array}$ & $\begin{array}{l}\text { COPD } \\
n=59\end{array}$ & $P$-value \\
\hline Age, years mean $\pm S D$ & $54.93 \pm 10.25$ & $61.92 \pm 10.28$ & $<0.00 \mathrm{I}$ \\
\hline Current smoker, n (\%) & 228 (7I.9) & $45(76.3)$ & 0.492 \\
\hline Pack-year, mean \pm SD & $53.61 \pm 33.10$ & $66.49 \pm 38.46$ & 0.009 \\
\hline Body mass index, mean $\pm S D$ & $29.28 \pm 5.00$ & $26.87 \pm 4.13$ & 0.001 \\
\hline Chronic cough, n (\%) & $115(36.3)$ & $52(88.1)$ & $<0.001$ \\
\hline Dyspnea, n (\%) & $194(61.2)$ & $55(93.2)$ & $<0.00 \mathrm{I}$ \\
\hline Wheezes, n (\%) & $73(23.0)$ & $32(54.2)$ & $<0.00 \mathrm{I}$ \\
\hline Chronic bronchitis, n (\%) & $48(15.1)$ & $4 \mathrm{I}(69.5)$ & $<0.00 \mathrm{I}$ \\
\hline Previous COPD diagnosis, $\mathrm{n}(\%)$ & $4(1.3)$ & $5(8.5)$ & $0.006^{\mathrm{a}}$ \\
\hline Diabetes mellitus, n (\%) & $126(39.7)$ & $22(37.3)$ & 0.723 \\
\hline Hypertension, n (\%) & $220(69.4)$ & $37(62.7)$ & 0.310 \\
\hline Hyperlipidemia, n (\%) & $88(27.8)$ & $12(20.3)$ & 0.236 \\
\hline \multicolumn{4}{|l|}{ Pre-bronchodilator } \\
\hline $\mathrm{FEV}_{1}, \mathrm{~L}$ & $2.7 I \pm 0.68$ & $2.06 \pm 0.71$ & $<0.00 \mathrm{I}$ \\
\hline $\mathrm{FEV}_{1}, \%$ predicted & $82.29 \pm|5.4|$ & $65.64 \pm|5.6|$ & $<0.00 \mathrm{I}$ \\
\hline $\mathrm{FEV}_{1} / \mathrm{FVC}$ ratio & $84.28 \pm 5.55$ & $63.46 \pm 6.98$ & $<0.001$ \\
\hline \multicolumn{4}{|l|}{ Post-bronchodilator } \\
\hline $\mathrm{FEV}_{1}, \mathrm{~L}$ & $2.80 \pm 0.79$ & $2.15 \pm 0.71$ & 0.008 \\
\hline $\mathrm{FEV}_{1}, \%$ predicted & $81.36 \pm 20.28$ & $68.25 \pm 15.82$ & 0.019 \\
\hline $\mathrm{FEV}_{1} / \mathrm{FVC}$ ratio & $79.73 \pm 5.68$ & $63.98 \pm 6.58$ & $<0.00 \mathrm{I}$ \\
\hline CAD & $246(77.6)$ & $54(91.5)$ & 0.014 \\
\hline \multicolumn{4}{|l|}{ Therapeutic strategy (CAD), $n(\%)$} \\
\hline Percutaneous angioplasty & $207(65.3)$ & $42(7 \mid .2)$ & $0.340^{\mathrm{a}}$ \\
\hline Coronary artery bypass surgery & $24(7.6)$ & $9(15.3)$ & \\
\hline Medical therapy & $15(4.7)$ & $3(5.1)$ & \\
\hline
\end{tabular}

Note: aFisher's exact test.

Abbreviation: CAD, coronary artery disease. those $\geq 70$ years, $P<0.001$. The pre-bronchodilator mean $\mathrm{FEV}_{1}, \%$ predicted was $65.64 \pm 15.61$ (range $31 \%-118 \%$ ) and the mean $\mathrm{FEV}_{1} / \mathrm{FVC}$ ratio was $63.46 \pm 6.98$ (range $39.0 \%-76.0 \%$ ) whereas the post-bronchodilator mean $\mathrm{FEV}_{1}$, $\%$ predicted was $68.25 \pm 15.82$ (range $45 \%-102 \%$ ) and the mean post-bronchodilator $\mathrm{FEV}_{1} / \mathrm{FVC}$ ratio was $63.98 \pm 6.58$ (range $37.0 \%-69.7 \%$ ).

Multivariate logistic regression with backward elimination was conducted to identify independent predictors of COPD among patients who underwent CATH (Table 3). In addition to coexisting $\mathrm{CAD}(\mathrm{OR}=3.16,95 \% \mathrm{CI} 1.10-9.09$, $P=0.033)$, increasing age $(\mathrm{OR}=1.07,95 \% \mathrm{CI} 1.03-1.10$, $P<0.001)$ and having chronic bronchitis (OR=13.07, 95\% CI 6.691-25.52, $P<0.001)$ were independent predictors of COPD.

\section{COPD and CAD}

COPD was more common in patients with CAD $(54 / 300$; $18.0 \%)$ compared to those without CAD $(5 / 76 ; 6.6 \%)$ ( $P=0.014)$. The prevalence of COPD was $16.1 \%$ in the medical therapy group, $16.9 \%$ in the PCI group, and $27.3 \%$ in the $\mathrm{CABG}$ group $(P=0.340)$. Similarly, the prevalence of COPD was not different between those who had singlevessel (17.1\%), two-vessel (17.1\%), or $\geq 3$-vessel (19.1\%) disease $(P=0.191)$. ANOVA combined with post hoc analysis (Table 4) showed that airflow limitation $\left(\mathrm{FEV}_{1}\right.$ 
Table 3 Multivariate logistic regression model for the predictors of COPD

\begin{tabular}{|c|c|c|c|c|}
\hline \multirow[t]{2}{*}{ Variables } & \multicolumn{2}{|c|}{ Univariate logistic regression } & \multicolumn{2}{|c|}{ Backward stepwise model } \\
\hline & OR (95\% Cl) & $P$-value & OR ( $95 \% \mathrm{Cl})$ & $P$-value \\
\hline \multicolumn{5}{|l|}{ COPD $(n=376)$} \\
\hline Coronary artery disease & $3.12(1.20-8.09)$ & 0.019 & $3.16(1.10-9.09)$ & 0.033 \\
\hline Age (years) & $1.07(1.04-1.10)$ & $<0.001$ & $1.07(1.03-1.10)$ & $<0.001$ \\
\hline Chronic bronchitis & $12.77(6.77-24.05)$ & $<0.001$ & | 3.07 (6.69-25.52) & $<0.001$ \\
\hline Pack-year & $1.01(1.00-1.02)$ & 0.011 & - & - \\
\hline Active vs ex-smoker & $1.26(0.66-2.40)$ & 0.492 & - & - \\
\hline
\end{tabular}

and $\mathrm{FEV}_{1}, \%$ ) was more prominent in patients who required $\mathrm{CABG}$ compared with patients without $\mathrm{CAD}(P=0.006$ and $P=0.018)$, respectively. However, there was no difference in airflow limitation among different groups of CAD treatment $(P>0.05)$.

\section{Discussion}

This study described the prevalence of COPD in a population of male smokers with angiographically proven CAD in a developing country. Our main findings showed high prevalence of undiagnosed COPD in patients with CAD, and that the risk of COPD was higher in older patients with respiratory symptoms.

Our results were consistent with previous reports on the increased prevalence of COPD in patients with CAD. ${ }^{9-12}$ A large multicenter study in Europe examined the prevalence of airflow limitation consistent with COPD in current and ex-smokers with ischemic heart disease. The prevalence of COPD ranged from $18.3 \%$ to $41.3 \%$, whereas $70.6 \%$ of all patients and one third of those with severe airflow limitation were underdiagnosed. In a study from Spain, 33.6\% of patients with CAD had air flow limitation consistent with COPD. Although they reported higher prevalence than this study, their patients were mostly older males, and those without CAD had a high prevalence of COPD (17.5\%). ${ }^{9}$ In Japan, the prevalence of COPD in patients with $\mathrm{CAD}$ ranged from
$10.5 \%$ to $25.9 \%{ }^{10,11}$ Most recently, a study from Spain used methodology and definitions similar to those in our study and showed that one fourth of patients who underwent PCI for CAD had COPD. ${ }^{12}$ Despite these consistent reports on the association between CAD and COPD, the latter is still largely underdiagnosed $\mathrm{d}^{9,11,12,18,19}$ and carries higher mortality and morbidity. ${ }^{12}$ In this study, the findings are in agreement with the inference in these reports: most patients with COPD who had CAD were not previously diagnosed. The low rate of diagnosis of COPD among our symptomatic heavy smokers is puzzling but in agreement with a previous study in primary care in Jordan. ${ }^{17}$ This may be partly explained by the lack of spirometry service in most primary-care centers in Jordan, by the notion that patients may be diagnosed with chronic bronchitis but not made aware of the diagnosis, or patients may simply deny having a disease that is strongly linked to their smoking habit.

Using a different methodology, epidemiological and hospital-based studies addressed the prevalence and risk of cardiovascular diseases including CAD in patients with an established diagnosis of COPD. ${ }^{7,23}$ Results of a meta-analysis showed a consistent increased risk (two- to five-fold) of CAD in patients with COPD relative to those without COPD. ${ }^{23}$ However, the risk appears to vary with the studied population, methodology of the study, and case definition. In the US population, $16.1 \%$ of patients with physician-diagnosed

Table 4 Spirometry findings according to therapeutic strategy of patients with coronary artery disease compared to patients without coronary artery disease

\begin{tabular}{lllllll}
\hline Parameters & No CAD & $\begin{array}{l}\text { Medical } \\
\text { therapy }\end{array}$ & PCI & CABG & ANOVA (F) & P-value \\
\hline FEV, L & $2.77 \pm 0.74^{\mathrm{a}}$ & $2.59 \pm 0.73$ & $2.61 \pm 0.7 \mathrm{I}$ & $2.28 \pm 0.67^{\mathrm{a}}$ & 3.66 & 0.013 \\
FEV,$\%$ predicted & $82.57 \pm 16.88^{\mathrm{b}}$ & $76.78 \pm 18.85$ & $79.96 \pm 16.43$ & $72.49 \pm 13.78^{\mathrm{b}}$ & 3.10 & 0.027 \\
FVC, L & $3.31 \pm 0.88$ & $3.20 \pm 0.88$ & $3.24 \pm 0.89$ & $2.90 \pm 0.93$ & 1.65 & 0.177 \\
FVC, \% predicted & $80.42 \pm 16.25$ & $78.17 \pm 16.37$ & $78.80 \pm 15.50$ & $72.24 \pm 16.20$ & 2.14 & 0.094 \\
FEV $/$ FVC ratio & $83.04 \pm 7.46$ & $79.28 \pm I 1.27$ & $80.75 \pm 9.52$ & $79.27 \pm 12.31$ & 1.78 & 0.150 \\
\hline
\end{tabular}

Note: a,blndicates significant $(P<0.05)$ difference between the groups using Tukey's HSD post hoc analysis.

Abbreviations: $C A D$, coronary artery disease; $\mathrm{PCl}$, percutaneous coronary intervention; $\mathrm{CABG}$, coronary artery bypass surgery. 
COPD had CAD, whereas $6.1 \%$ of patients without COPD had CAD. Patients with COPD were twice as likely to have $\mathrm{CAD},{ }^{24}$ and this risk appears to be two times higher in those $>60$ years of age. ${ }^{25}$ In a UK primary-care setting, the risk of acute myocardial infarction in patients with established diagnosis of COPD can be as high as ten-fold. ${ }^{26}$ Finally, in various European populations, the prevalence of CAD in patients with COPD ranged from $14 \%$ to $30 \%{ }^{23}$

Reports from developing countries on the association between COPD and CAD are scarce. In a small study from Sudan, $28 \%$ of patients with angiographically conformed $\mathrm{CAD}$ had $\mathrm{FEV}_{1}<80 \%$ and were considered to have COPD. Another study from Pakistan found that one third of patients with CAD (based on ECG criteria) had COPD (FEV $/$ FVC ratio $<70 \%$ ). Lastly, a large regional epidemiological study on the prevalence and impact of COPD in the Middle East and North Africa (BREATHE study) showed that the overall prevalence of COPD was $3.6 \%$ (ranging from $1.9 \%$ to $6.1 \%$ ), ${ }^{16}$ and one fourth of all subjects with COPD reported having coexisting cardiovascular disease. ${ }^{27}$ Our results are comparable to these regional studies, with almost one-in-five men with CAD having COPD. The prevalence of COPD in subjects without $\mathrm{CAD}(6.6 \%)$ is comparable to what has been reported in the general population in Jordan $(5.4 \%-8.2 \%) .{ }^{16,17}$

This significant association may be explained by the shared enhanced systemic inflammatory biomarkers including interleukin 6, C-reactive protein, and fibrinogen in patients with COPD and CAD, ${ }^{5,6}$ which is more prominent during COPD exacerbations. ${ }^{28}$ Moreover, hypoxic stress and the impaired arterial flow-mediated dilation in $\mathrm{COPD}^{29}$ may result in vascular dysfunction that is noted in patients with COPD. The prevalence of both COPD and CAD increases with advancing age. In this study, the prevalence of COPD increased from $6.5 \%$ in younger patients to $37.5 \%$ in the older ones. Lastly, our patient population showed a high smoking intensity - a shared risk factor for both diseases.

The coexistence of COPD and CAD is detrimental and associated with a negative impact on the outcome of the affected individuals. Patients with undiagnosed COPD who undergo PCI have higher morbidity and mortality, ${ }^{12,13}$ and cardiovascular comorbidity increases the burden of patients with COPD as more than a quarter of patients with COPD die of cardiovascular disease. ${ }^{14,30}$ Moreover, patients admitted for COPD exacerbation were found to have a high troponin level in the absence of acute coronary symptoms and a subsequent coronary angiography showed significant coronary stenosis. ${ }^{31}$ A recent extended follow-up study on patients with CAD showed persistent increase of cardiovascular mortality in patients with coexisting COPD. ${ }^{32}$ Additionally, when treating patients who are diagnosed with both COPD and $\mathrm{CAD}$, the long-term use of beta- 2 agonists is considered a safe practice, ${ }^{33}$ and the use of cardio-selective beta-blockers in CAD may even lower the mortality of patients with COPD. Lastly, statins - commonly used in patients with CAD - may be helpful in treating coexisting COPD. ${ }^{34}$

In this study, there was a trend toward increased prevalence of COPD in patients who were referred for $\mathrm{CABG}$ compared with those who had PCI or medical therapy, but the difference was not statistically significant. Similarly, there was no increase in prevalence with increasing number of diseased coronary vessels. These findings may be partially explained by the lack of power in this study to detect the differences as well as by the notion that choice of therapy may be influenced by other factors beside the severity and complexity of the coronary disease. Moreover, the sole use of the number of vessels to stratify the severity of CAD has limitations, ${ }^{35}$ and a more comprehensive angiographic scoring system has been developed to better define the severity and prognosis of coronary atherosclerosis. ${ }^{36,37}$

This study had number of limitations that merit consideration. The study sample was recruited from a single referral center in Jordan, and women were not included in the analysis. Women represented $<5 \%$ of smokers who had coronary angiography, and national data in Jordan showed that whereas one in two adult men smoke cigarettes, only $5 \%$ of women were regular smokers. This may limit the generalization of the results to the general population in Jordan and to other countries in the region. Furthermore, the study excluded patients with CAD and a smoking history of less than 10 pack-years and this may have resulted in an overestimation of the prevalence of COPD. In contrast, the study did not include patients with acute myocardial infarction and patients who were too ill to carry out spirometry, which may have resulted in a lower prevalence of COPD. Finally, the study was cross-sectional in nature and, therefore, was not intended to identify the impact of this strong association on short- and long-term morbidity and mortality of patients with CAD. Further multicenter and longitudinal studies using a robust scoring system of the severity of CAD are needed to address the impact of airflow limitation and COPD on the outcomes of patients with CAD in developing countries.

\section{Conclusion}

There was a high prevalence of COPD among male patients with CAD and most were underdiagnosed despite having respiratory symptoms. Smoking men with CAD and respiratory symptoms should be evaluated for airflow limitation and the presence of COPD. 


\section{Acknowledgment}

The authors thank Mr Bryan Simmons for proofreading the manuscript.

\section{Disclosure}

The authors report no conflicts of interest in this work.

\section{References}

1. Global Initiative for Chronic Obstructive Lung Disease (GOLD). The Global Strategy for the Diagnosis, Management and Prevention of COPD; 2017. Available from: http://goldcopd.org. Accessed May 20, 2017.

2. Lopez AD, Shibuya K, Rao C, et al. Chronic obstructive pulmonary disease: current burden and future projections. Eur Respir J. 2006; 27(2):397-412.

3. Nichols M, Townsend N, Scarborough P, Rayner M. Cardiovascular disease in Europe 2014: epidemiological update. Eur Heart J. 2014; 35(42):2929-2959.

4. Benjamin EJ, Blaha MJ, Chiuve SE, et al. Heart Disease and Stroke Statistics-2017 Update: A Report From the American Heart Association. Circulation. 2017;135(10):e146-e603.

5. Celli BR, Locantore N, Yates J, et al. Inflammatory biomarkers improve clinical prediction of mortality in chronic obstructive pulmonary disease. Am J Respir Crit Care Med. 2012;185(10):1065-1072.

6. Maclay JD, Macnee W. Cardiovascular disease in COPD: mechanisms. Chest. 2013;143(3):798-807.

7. Müllerova H, Agusti A, Erqou S, Mapel DW. Cardiovascular comorbidity in COPD: systematic literature review. Chest. 2013;144(4): 1163-1178.

8. Schnell K, Weiss CO, Lee T, et al. The prevalence of clinically-relevant comorbid conditions in patients with physician-diagnosed COPD: a cross-sectional study using data from NHANES 1999-2008. BMC Pulm Med. 2012;12:26.

9. Soriano JB, Rigo F, Guerrero D, et al. High prevalence of undiagnosed airflow limitation in patients with cardiovascular disease. Chest. 2010;137(2):333-340.

10. Wada H, Nakano Y, Nagao T, et al. Detection and prevalence of chronic obstructive pulmonary disease in a cardiovascular clinic: evaluation using a hand held $\mathrm{FEV}_{1} / \mathrm{FEV}_{6}$ meter and questionnaire. Respirology. 2010;15(8):1252-1258.

11. Onishi K, Yoshimoto D, Hagan GW, Jones PW. Prevalence of airflow limitation in outpatients with cardiovascular diseases in Japan. Int $J$ Chron Obstruct Pulmon Dis. 2014;9:563-568.

12. Almagro P, Lapuente A, Pareja J, et al. Underdiagnosis and prognosis of chronic obstructive pulmonary disease after percutaneous coronary intervention: a prospective study. Int J Chron Obstruct Pulmon Dis. 2015;10:1353-1361.

13. Zhang M, Cheng YJ, Zheng WP, et al. Impact of Chronic Obstructive Pulmonary Disease on Long-Term Outcome in Patients with Coronary Artery Disease Undergoing Percutaneous Coronary Intervention. Biomed Res Int. 2016;2016:8212459-6.

14. Calverley PM, Anderson JA, Celli B, et al. Cardiovascular events in patients with COPD: TORCH study results. Thorax. 2010;65(8): 719-725.

15. Aït-Khaled N, Enarson D, Bousquet J. Chronic respiratory diseases in developing countries: the burden and strategies for prevention and management. Bull World Health Organ. 2001;79(10):971-979.

16. Tageldin MA, Nafti S, Khan JA, et al. Distribution of COPD-related symptoms in the Middle East and North Africa: results of the BREATHE study. Respir Med. 2012;106(Suppl 2):S25-S32.

17. Al Omari M, Khassawneh BY, Khader Y, Dauod AS, Bergus G. Prevalence of chronic obstructive pulmonary disease among adult male cigarettes smokers: a community-based study in Jordan. Int J Chron Obstruct Pulmon Dis. 2014;9:753-758.
18. Ahmed AH, Yagoub TE, Muthana F. Prevalence of chronic obstructive pulmonary disease in patients with catheter-diagnosed coronary artery disease. Ann Thorac Med. 2009;4(2):91-92.

19. Ullah R, Salam S, Ghaffar T, Muhammad R, Khan I. Frequency Of Undiagnosed Chronic Obstructive Pulmonary Disease In Patients With Coronary Artery Disease. J Ayub Med Coll Abbottabad. 2017;29 (2):285-288.

20. van der Molen T, Willemse BW, Schokker S, Ten Hacken NH, Postma DS, Juniper EF. Development, validity and responsiveness of the Clinical COPD Questionnaire. Health Qual Life Outcomes. 2003; 1(1):13.

21. Global Initiative for Chronic Obstructive Lung Disease. GOLD spirometry guide; 2010. Available from: http://goldcopd.org/gold-spirometryguide/. Accessed May 20, 2017.

22. Pellegrino R, Viegi G, Brusasco V, et al. Interpretative strategies for lung function tests. Eur Respir J. 2005;26(5):948-968.

23. Chen W, Thomas J, Sadatsafavi M, Fitzgerald JM. Risk of cardiovascular comorbidity in patients with chronic obstructive pulmonary disease: a systematic review and meta-analysis. Lancet Respir Med. 2015;3(8):631-639.

24. Finkelstein J, Cha E, Scharf S. Chronic obstructive pulmonary disease as an independent risk factor for cardiovascular morbidity. Int J Chron Obstruct Pulmon Dis. 2009;4:337-349.

25. Franssen FME, Soriano JB, Roche N, et al. Lung Function Abnormalities in Smokers with Ischemic Heart Disease. Am J Respir Crit Care Med. 2016;194(5):568-576.

26. Feary JR, Rodrigues LC, Smith CJ, Hubbard RB, Gibson JE. Prevalence of major comorbidities in subjects with COPD and incidence of myocardial infarction and stroke: a comprehensive analysis using data from primary care. Thorax. 2010;65(11):956-962.

27. Uzaslan E, Mahboub B, Beji M, et al. The burden of chronic obstructive pulmonary disease in the Middle East and North Africa: results of the BREATHE study. Respir Med. 2012;106(Suppl 2):S45-S59.

28. Hurst JR, Perera WR, Wilkinson TM, Donaldson GC, Wedzicha JA. Exacerbation Of Chronic Obstructive Pulmonary Disease: Pan-Airway and Systemic Inflammatory Indices. Proc Am Thorac Soc. 2006;3(6): $481-482$.

29. Eickhoff P, Valipour A, Kiss D, et al. Determinants of Systemic Vascular Function in Patients with Stable Chronic Obstructive Pulmonary Disease. Am J Respir Crit Care Med. 2008;178(12):1211-1218.

30. Huiart L, Ernst P, Suissa S. Cardiovascular Morbidity and Mortality in COPD. Chest. 2005;128(4):2640-2646.

31. Pizarro C, Herweg-Steffens N, Buchenroth M, et al. Invasive coronary angiography in patients with acute exacerbated COPD and elevated plasma troponin. Int J Chron Obstruct Pulmon Dis. 2016;11: 2081-2089.

32. Almagro P, de La Sierra A, Acosta E, et al. Spirometrically Confirmed Chronic Obstructive Pulmonary Disease Worsens Long-Term Prognosis after Percutaneous Coronary Intervention. Am J Respir Crit Care Med. 2018;197(6):824-826.

33. Decramer ML, Hanania NA, Lotvall JO, Yawn BP. The safety of longacting beta2-agonists in the treatment of stable chronic obstructive pulmonary disease. Int J Chron Obstruct Pulmon Dis. 2013;8:53-64.

34. Zhang W, Zhang Y, Cw L, Jones P, Wang C, Fan Y. Effect of Statins on COPD: A Meta-Analysis of Randomized Controlled Trials. Chest. 2017;152(6):1159-1168.

35. Ringqvist I, Fisher LD, Mock M, et al. Prognostic value of angiographic indices of coronary artery disease from the Coronary Artery Surgery Study (CASS). J Clin Invest. 1983;71(6):1854-1866.

36. Farooq V, van Klaveren D, Steyerberg EW, et al. Anatomical and clinical characteristics to guide decision making between coronary artery bypass surgery and percutaneous coronary intervention for individual patients: development and validation of SYNTAX score II. Lancet. 2013;381(9867):639-650.

37. Neeland IJ, Patel RS, Eshtehardi P, et al. Coronary angiographic scoring systems: an evaluation of their equivalence and validity. Am Heart $J$. 2012;164(4):e541:547-552. 


\section{Publish your work in this journal}

The International Journal of COPD is an international, peer-reviewed journal of therapeutics and pharmacology focusing on concise rapid reporting of clinical studies and reviews in COPD. Special focus is given to the pathophysiological processes underlying the disease, intervention programs, patient focused education, and self management protocols.

This journal is indexed on PubMed Central, MedLine and CAS. The manuscript management system is completely online and includes a very quick and fair peer-review system, which is all easy to use. Visit http://www.dovepress.com/testimonials.php to read real quotes from published authors.

Submit your manuscript here: http://www.dovepress.com/international-journal-of-chronic-obstructive-pulmonary-disease-journal 